\title{
Exploring Open Innovation at the Level of R\&D Projects
}

\author{
Wim Vanhaverbeke, Jingshu Du, Bart Leten, \\ and Ferrie Aalders
}

\subsection{INTRODUCTION}

Firms are increasingly adopting open innovation strategies in their innovation activities (Huston \& Sakkab, 2007; Kirschbaum, 2005; Van den Biesen, 2008). In the last two decades, several factors pushed companies to source technologies from external parties and monetize their unused technologies through licensing agreements or spin-offs. The increasing complexity of technologies (Brusoni, Prencipe \& Pavitt, 2000), the (typical) over-utilization of own R\&D personnel (Clark \& Wheelright, 1990), the specialization of technology players such as universities and high tech start-ups and the emergence of more effective technology markets with new types of intermediaries and technology services companies as main growth accelerators are important drivers of the popularity of open innovation among practitioners (Chesbrough, 2003a, 2006a).

Research on open innovation has been burgeoning in the wake of the increasing role of open innovation in companies. Yet, despite its popularity, the actual performance effects of open innovation are not well understood. R\&D collaboration with external partners is an important element of outside-in open innovation activities. Over the past years, several studies have examined the performance effects of R\&D collaborations. These studies have almost exclusively focused on the firm level. So far, no consensus has been reached in the literature (see Tsai et al., 2009 for an overview). Some studies show that R\&D collaborations improve firm performance (e.g.: Shan et al., 1994; Dodgson et al., 2006; Sivadas \& Dwyer, 2000; Tether, 2002; Becker \& Dietz, 2004; Belderbos et al., 2004; Sofka \& Grimpe, 2010), while other studies find no or negative effects of collaborations (e.g.: Campbell \& Cooper, 1999; Knudsen \& 
Mortensen, 2011; Kessler et al., 2000; Bougrain \& Haudeville, 2002; Schulze \& Hoegl, 2008). Besides these conflicting findings, still some other studies argue that collaboration has a mixed effect on firm performance (e.g.: Laursen \& Salter, 2006; Faems et al., 2010; Hopkins et al., 2011; Gassmann \& Enkel, 2010), depending on a number of contingency factors such as the composition of the alliance portfolio and the performance dimension that is studied.

There are several possible explanations why researchers end up with different results, but one straightforward reason is that most studies aggregate different project level practices to general concepts at the firm level that are then linked to firm level performance indicators. As such, the firm has long been treated as a "black box", possibly leading to a number of seemingly contradictory findings on the effect of open innovation. In practice, a firm's performance can be influenced by many factors in the "black box" which are not related to its choice for open or closed innovation. A company may have developed poor business models for some of the technologies that it is working on: in that case an innovation will fail even though collaboration with innovation partners has been managed properly. In other cases, some R\&D activities might not be in alignment with the needs of the business groups of the company (Chesbrough, 2003a). The breach between the R\&D projects and the operational businesses will finally lead to suboptimal performance levels even when the company has developed best practices to team up with external partners in technology development. These are only a few examples of the many contingencies that might introduce noise in the relationship between open innovation and firm level performance. Therefore, it is not surprising that empirical research at the firm level may result in divergent outcomes.

One way to tackle these problems is by lowering the level of open innovation research from the firm to the $\mathrm{R} \& \mathrm{D}$ projects where open innovation activities take place. This allows controlling for the peculiarities of the $\mathrm{R} \& \mathrm{D}$ projects. Having not gained enough attention in the open innovation literature, R\&D projects have been investigated in detail in the new product development (NPD) literature. The focus of this literature stream is however mainly, if not exclusively, on factors internal to the firm, such as project leadership, team composition, management support, process management, and cross-functional integration (Brown \& Eisenhardt, 1995; Cooper et al., 2004; Kahn et al., 2006; Griffin, 1997; Carlile, 2002). With the exception of a few studies that look at customer/supplier integration in the $\mathrm{R} \& \mathrm{D}$ project (e.g.: Ragatz et al., 1997; Campbell \& Cooper, 1999; Ma et al., 2012; Bahemia \& Squire, 2010), the NPD literature has paid limited attention to external collaboration and partnership on project performance, particularly not to the involvement of technologybased partners, such as universities and knowledge institutes. Given the growing trend of companies to conduct $R \& D$ projects in collaboration with external partners, it is important to investigate the effect of open innovation collaboration at the project level (Du, Leten, and Vanhaverbeke, 2014). Yet, the NPD 
literature never systematically examined the effect of $R \& D$ collaboration with external partners on NPD performance, nor did it consider R\&D collaboration as one of the critical success factors to project performance.

Furthermore, considering partnerships at the project level is also necessary given the limitations of the current NPD literature stream. Although operational improvements have been made over the past decades, the success rate of R\&D projects has remained surprisingly stagnant (Page, 1993; Griffin, 1997; Cooper et al., 2004; Barczak et al., 2009). A possible reason for this might be that there are some factors which are critical to project success but have not yet been identified in the NPD literature. Opening up and collaborating with external partners on R\&D activities might be one such factor. ${ }^{1}$

In sum, the NPD literature has been largely silent about the impact of external collaboration on project performance, while the open innovation literature has analyzed the impact of external collaboration mainly at the firm level. Little is therefore known whether and how collaboration with external partners affects performance at the $\mathrm{R} \& \mathrm{D}$ project level.

\subsection{WHY ANALYZE OPEN INNOVATION AT THE R\&D PROJECT LEVEL?}

As discussed before, one way to develop a more thorough understanding of open innovation is to analyze it at sub-firm levels of analysis. Responding to the call of West, Vanhaverbeke and Chesbrough (2006, pp. 287-301), the analysis of open innovation at the firm level needs to be complemented with analyses at other levels. $\mathrm{R} \& \mathrm{D}$ projects offer in this respect an interesting platform to study open innovation. We discuss some reasons below why this is the case.

First, firms typically organize innovation activities in $\mathrm{R} \& \mathrm{D}$ projects, and that increasingly more organizations switch to project-based forms (Hobday, 2000; Sydow et al., 2004). In practice, decisions on collaboration are taken on the project level rather than at the firm level, based on innovation needs and missing competencies. To understand the benefits (or drawbacks) of open innovation, we have to understand how openness functions within $\mathrm{R} \& \mathrm{D}$ projects.

Second, R\&D projects offer fine-grained information about the innovation activities in large firms. Apart from providing in-depth information on collaboration with external partners, $R \& D$ projects offer information on the peculiarities of projects. R\&D projects may differ in many respects: the technology developed in projects may be different (radical vs. incremental, modular vs. architectural, etc.), projects vary in terms of budgeted resources, the leadership and team composition may be different and the innovation partner types might vary across projects. R\&D projects show in detail how firms develop new technologies: When we study open innovation at the R\&D project level, 
we no longer consider the firm as a black box where we argue -with the help of theoretical concepts (e.g. search breadth and depth, ambidexterity, absorptive capacity) - that openness will or will not lead to better firm level performance. At the R\&D project level, we can control for the particularities of R\&D projects and therefore we may monitor more directly the relation between open innovation and performance.

Third, aggregating information at the firm level always implies that there is a loss of valuable information. Relationships that are found may be driven by a few outlier projects. For instance, it may be possible that within a firm, the majority of projects are closed, but only a few projects are open. Assume that these few open projects generate very high financial returns or patent applications. In this case the overall collaboration intensity of the firm is low (because the majority of the projects are closed), but the performance can be high (because of the few projects that are open). An analysis at the firm level will mistakenly lead to the conclusion that a low level of open innovation is beneficial for a company. An analysis at the R\&D project level will lead to opposite (but correct) conclusions.

Fourth, a detailed analysis of open innovation at the R\&D project level extends the list of critical success factors which determine performance. Factors such as team composition, team leader profile, R\&D project management techniques, and the way of interactions with external partners as well as with other departments/projects within the firm, may enrich our understanding of the boundary conditions under which open innovation can work. Therefore, analyzing open innovation at the $\mathrm{R} \& \mathrm{D}$ project level may facilitate project-level decision-making and improve management effectiveness. R\&D projects face strict budget and time constraints, and $\mathrm{R} \& \mathrm{D}$ project managers should only decide to engage external partners when their input is really necessary. Therefore, if we understand how open innovation functions at the project level, we may help making better decisions in conceiving, setting up, and running R\&D projects.

In the next section we give a detailed description how $\mathrm{R} \& \mathrm{D}$ projects are organized and managed in large companies. Researching open innovation at the $R \& D$ project level cannot be done without a salient insight in what $R \& D$ projects are and how external partners play a role during an R\&D project.

\subsection{ANALYZING OI R\&D PROJECTS IN LARGE COMPANIES}

We can only study how open innovation affects project performance if we have a good understanding of how large companies set up and organize $R \& D$ projects. In this section we give a detailed description of how $R \& D$ projects are structured 
and managed in large firms, exemplified by $\mathrm{R} \& \mathrm{D}$ projects developed in the central research units of Royal Philips. This description is instrumental to providing us a more nuanced picture about the differences of open innovation activities conducted at the R\&D project level and at the firm level, and how and when open innovation improves innovative and financial performance (see also $\mathrm{Du}$, Leten, and Vanhaverbeke, 2014).

R\&D projects have a lifetime; they are typically terminated a few years after initiation. Proposals for new R\&D projects can be specified by business groups in the company, top management, or by the central research unit itself. Only the most promising projects are selected, as annual budgets for R\&D are restricted. Once selected, management agrees upon specific targets for each project, projects are budgeted, and a team of scientists and engineers are assigned to the project. A project leader manages the progress: most likely (s) he has been involved previously in other projects and preferably (s)he has been already a project leader in the past.

$\mathrm{R} \& \mathrm{D}$ projects are evaluated regularly (annually) and discontinued if they are not living up to expectations. In case of a negative evaluation, financial and human resources are released and reassigned to other more promising projects. A transfer takes place when the technological results of a R\&D project are interesting enough for an internal recipient or "customer"-a business group, the central research unit, the IP department or one of the corporate incubators. A transfer of project results takes place when knowledge is purposefully disclosed to a customer of Philips Research under specific conditions:

- When the customer agrees to apply this knowledge in his/her business in (pre)-development projects, products, processes or services;

- When the customer recognizes this knowledge as adding value;

- When the customer takes action to absorb this knowledge in his/her operations to enable an application.

A transfer is only completed when the internal customer confirms these conditions. A project can transfer results to multiple business units using the same technology in different products, markets, or applications.

This short overview about how $\mathrm{R} \& \mathrm{D}$ projects are typically processed in large manufacturing firms raises automatically the question what success means in this context. We can rely on at least three indirect indicators that jointly provide an indication of the innovation success of research projects. The three indicators are transfer volume, transfer speed, and the business value of transfers.

Transfer volume measures the number of transfers from Corporate Research to the business groups. An R\&D project could generate one or more transfers but many projects may not create any transfer to an internal business unit. Still, in that case, the company can generate extra income through licensing agreements. The total number of transfers is a first proxy for success when the analysis is done at the project level. 
Transfer speed: This measure of open innovation success is defined as the elapsed time between the start of a project and the date of transfer of the technology to a business unit (development speed) or between the transfer date and the initial market sales (speed to market). The development speed can be divided in two parts: the first part is the elapsed time between the start of the project to its first transfer; the second part takes into account all transfers generated by an $\mathrm{R} \& \mathrm{D}$ project and is calculated as the average time between the start of the project and all the transfers a project generates.

Business success: Technology transfers are reviewed annually on their business success. In Philips, business success can have the following status:

- Business Success: delivering €25 million or more in turnover in a given year. Turnover is taken as a measure of success (and value) of a transfer;

- Potential Business Success: expected to become a business success in the foreseeable future (less than 5 years);

- Old Business Success: a previous business success, but no longer so;

- Inactive: the business opportunity is no longer pursued;

- Transfer: Transfer without a direct prospect of becoming a business success.

The status of a transferred technology is an interesting variable to get a better insight in which transfers (or projects) result in a (major) business success, how long it takes to reach business success, and whether (and why) some projects are more successful in generating new businesses based on the transferred technology.

When a company is recording its patenting activities meticulously, there is also a possibility to have an indication of the success of $\mathrm{R} \& \mathrm{D}$ projects in terms of patent applications or patent grants. Many large companies systematically patent technological inventions and most of them can be linked to one (or a few) particular R\&D project(s). Therefore, patent application or patent grants can be used as an alternative (although different indicator) of the technology success of a project (besides transfers). Patent application has been a popular indicator of technical performance for decades. Despite its popularity, however, there has been great concern about the reliability of patenting as an output indicator (see, e.g. Basberg, 1987; Griliches, 1990). This concern stems from at least four aspects of consideration: the technological level and the economic value of patents are highly heterogeneous; the tendency to bundle patent claims together in one or more patents varies widely among countries; not all innovations are patented; not all patents become innovations. Patent applications only reflect the innovativeness of the invention, while giving little indication of the commercial value of potential applications. In large companies the majority of the patents do not make a contribution to a firm's performance. 
Also, patenting can carry significant strategic considerations. Therefore, patents are rather a raw indicator of firms' innovative activities. In this sense, transfer related indicators might be a welcome alternative to estimate success in innovation studies.

Innovation performance is a multi-dimensional concept and should be measured in different ways. Moreover, the different indicators of success at the project level have nothing in common with the success metrics at the firm level: this already indicates that project and firm level investigations of the impact of open innovation on innovation success are complementary to each other. What these two levels of analysis consider as success are different concepts. So far we have not described how open innovation at the R\&D project level has an effect on performance. Open innovation can be introduced in different ways: At Philips Research, partners are categorized as in Figure 6.1.

Two types of partners are distinguished: technology-based partners and market-based partners. In line with the flow of knowledge and technology, these are also referred to in the company as "upstream" or "downstream" partners, respectively.

$\mathrm{R} \& \mathrm{D}$ projects can be executed internally or in collaboration with external partners. At Philips, management makes a distinction between technology-based partners and market-based partners. Technology-based collaboration indicates that a project is executed in cooperation with academic institutes, government agencies, or organizations in other industries. Market-based collaboration indicates that a project is executed in cooperation

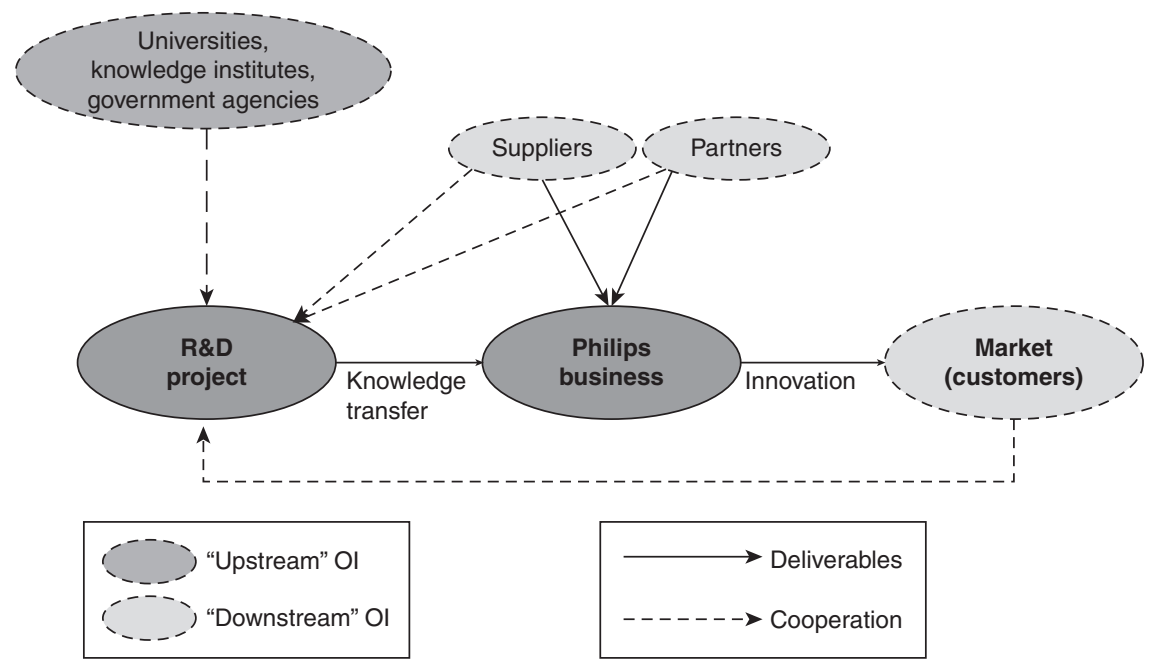

Figure 6.1 Graphical representation of Philips open innovation process 
with customers, partners, or suppliers of Philips businesses. Depending on project needs, a choice is made between partners.

Open innovation can be operationalized in different ways depending on the availability of the information (archived data, reports, etc.). Some companies will only register whether or not they collaborate with partners. Other companies record the names of partners which may enrich the analysis substantially. When partners are identified, research can take into account the identity of partners, and examine the role of industry or technological distance between the focal firm and its partner(s) in a project, the role of the geographical and cultural distance between partners, the role of trust building when companies work together with partners with whom they have been working together before. It is well known that "familiarity breeds trust" between alliance partners (Gulati, 1995). Prior relationships with partners could increase the success rate of $\mathrm{R} \& \mathrm{D}$ projects. Good cooperation with partners in previous projects also explains why companies prefer to work again with the same partners rather than trying out new ones. It however may also entail a risk. New partners are more likely to come up with new technologies and business ideas, compared to existing partners. Therefore, it might be interesting to look for new partners when technology is changing rapidly. Furthermore, one could distinguish between different types of partners, such as collaboration with universities, or small start-ups compared to collaboration with large companies. Besides focusing on single types of partner, it would also be interesting to look at the different types of partners collaborating in larger innovation ecosystems.

When information about collaboration with external partners is gathered systematically over time, one can investigate the evolution of partnerships and examine the role of the duration of R\&D collaborations, focusing on factors such as collaboration continuity. Time-varying variables introduce a whole wave of new research topics such as the optimal duration of collaboration and the role of simultaneous collaboration with different types of partners versus a sequential approach with different types of partners. In case a sequential approach is beneficial for the innovative performance of the company one has to look which sequence of collaboration with different actors leads to the best results.

There are several other ways to strengthen the inquiry of the role of open innovation in $R \& D$ projects. Two examples may illustrate this. First, governance modes play a crucial role in the innovative success of collaborative projects. Contractual arrangements, non-equity alliances, strategic supplier agreements, and joint development agreements are just a few examples how open innovation takes shape. Finding the right contractual arrangement with different types of partners is crucial in determining the success of R\&D projects. This, however, requires the availability of data about contractual agreements. Second, the success of a project is not only determined by the collaboration with external partners, both closed and open innovation projects are tapping into internal capabilities of the firm. Projects can leverage intra-firm networks and benefit 
from internal collaborations with other departments. Some managers are more skillful than others to detect and mobilize internal resources for R\&D projects. Especially the relationships with managers in different businesses of the company may be instrumental in generating one or more technology transfers. Data about internal networks in many cases are not recorded, but it is obvious that internal networks and support are as essential as the input from external partners. Proxies of internal networks could be generated via secondary data, such as information on co-ownership and citations in patents and publications. We hope that some scholars will take up this challenge in the next years.

\subsection{HOW DOES OPEN INNOVATION AFFECT R\&D PROJECT SUCCESS?}

How does open innovation in large innovative companies have an impact on the success of $\mathrm{R} \& \mathrm{D}$ projects? The effect is likely to be influenced by a range of factors: the type of partners involved in collaboration, the phase of project development in collaboration, the organizational modes chosen for collaboration, as well as the technology fields involved in the collaboration, just to name a few. Project success can be measured in different ways (Swink et al., 2006): we use three proxies to represent project success: transfer volume, transfer speed and business success as explained in section 6.3. Below we describe how three types of factors-type of partners, phases in the project, and modes of collaboration-may influence the impact of open innovation on project performance. We cannot discuss all possible factors but we try to cluster them under several headings at the end of this section.

\subsubsection{Type of Partners and R\&D Project Success}

An $R \& D$ project team may collaborate with different types of partners. Each type of partner has different capabilities and incentives to collaborate. For instance, market-based partners have expertise and knowledge on market needs (von Hippel, 2005; Prahalad \& Ramaswamy, 2004a) and the latest technologies, parts and components that are available to satisfy these needs. They help a new product to establish a foothold in the marketplace (Appiah-Adu \& Ranchhod, 1998) by eliminating the likelihood of product failures (Harrison \& Waluszewski, 2008) and meeting customer satisfaction (Ragatz, Handfield \& Peterson, 2002; Gruner \& Homburg, 2000). Technology-based partners are experts in (basic) scientific research and provide project teams with knowledge on the latest scientific developments. Scientific knowledge may function as a "map" for scientific research and point R\&D teams to the most profitable directions for applied 
research. Further, this knowledge may help teams to evaluate the outcomes of applied research (Rosenberg, 1990; Fleming \& Sorenson, 2004; Cassiman et al., 2008). Because of their different roles, collaboration with these two types of partners will likely have a different impact on project performance.

Cooperation with technology partners may increase the chance of project success in the following aspects:

- Higher speed of knowledge transfer using scientific knowledge:

Technology partners provide project teams with (basic) scientific knowledge, which is complementary to the applied knowledge of project teams. Partnerships with complementary partners allow for a partition of project tasks among partners and to benefit from a division of labor. Working in parallel on different tasks will likely result in a higher product development speed.

- Higher volume of knowledge transfer through more frequent science-related additions:

Collaboration with technology partners may lead to the generation of new platform technologies that rely on the latest scientific insights. Platform technologies are cost-efficient as they allow for the generation of a family of derivative innovations or product line additions at low costs. Platform technologies will lead to a higher transfer volume per R\&D project.

- Greater business value of knowledge transfer through higher speed and introduction of cutting-edge science:

Collaboration with technology partners speeds up technology development, which gives an innovation firm the opportunity to be a first mover on the market, to outcompete competitors, and to have a larger market share in growth markets. Further, technology partners infuse innovations with the latest scientific insights. Innovations incorporating latest technologies are high risk bets: they are risk laden but they may result in the most promising business opportunities. Exploring the technological frontier, and collaborating with technology partners, is one way for companies to create options for new business opportunities.

Collaboration with market partners may also increase the chance of project success through:

- Higher speed of knowledge transfer using market knowledge:

Market partners have more and more specific information about customer needs, market trends, and foresight. Collaboration with these partners sheds light on the latest market knowledge. This increases the chance that developed technologies become a market success. The innovating firm can quickly transfer technologies if managers of business units perceive that the technological solutions are targeting real market needs. 
- Higher volumes of knowledge transfers:

Market-based partners inform the firm about market trends and customer needs, which makes the output of the research more valuable for the latter. Better market information and market preparation leads to a more correct estimation of business opportunities and fewer market failures. Therefore, we can expect that collaboration with market partners will on average result in higher business value of knowledge transfers.

- Downstream open innovation is not increasing the chance of greater business success through higher volume of knowledge transfer:

Information about particular market opportunities from market-based partners will not lead to more frequent additions to technology. In contrast with collaboration with technology partners, collaboration with market-based partners will not increase the volume of transfers.

The joint use of technology-based and market-based collaboration may also be useful. For instance, business success may be better guaranteed when technology-based and market-based collaboration are combined, as the product is built on the combination of leading edge scientific insights and technologies and a thorough understanding of market trends and needs. However, R\&D projects where both technology and market partners are involved may be more complex and harder to manage than closed innovation projects, or projects that involve one type of partner. Because of the distinct nature of these types of partners, their goals and working habits are likely to be different. Compared to closed innovation $\mathrm{R} \& \mathrm{D}$ projects or projects that only collaborate with one type of partner, communication and coordination of projects that collaborate with both types of partners can be more challenging. Therefore we expect that collaboration with the two types of partners will not be efficient for small projects. The larger the projects, the easier it is to deliver the extra investment related to collaboration with different partners.

\subsubsection{Phase of Project Development in Collaboration and R\&D Project Success}

Not only the type of R\&D partners but also the timing of collaboration may have an impact on the success of open innovation projects. Collaborations may take place at different time points of an R\&D project. Projects dynamically evolve over time into further development stages, and in each phase, its goals, needs, and activities are different. Therefore, interactions with external partners may differ from phase to phase. However, the majority of studies have a static view. Success factors are considered to have the same impact on the success of R\&D projects regardless their development phase (Pinto \& Prescott, 1988). 
The NPD literature has generally defined four phases of product development: initialization (also called "conceptualization" or "fuzzy front end"), planning, execution, and termination (e.g.: King \& Cleland, 1983; Clark \& Wheelwright, 1990). In the context of open innovation, R\&D collaborations can take place in one or several of these phases. For each of these phases, project performance is likely to be influenced by external partnerships in different ways.

In the project initialization phase, project development is still in its fuzzy front end, the initial investment and commitment to the project is relatively small compared to the more expensive later project phases (Cooper, 1990; Van Oorschot et al., 2010). The project enjoys greater flexibility and multiple possibilities in making choices on its way to proceed (Pinto \& Prescott, 1988). A large amount of information is needed to ensure the technology is feasible and market-opportunities are tangible. Moreover, costs for trials and experimentation are small in this phase (Van Oorschot et al., 2010). As external partnerships provide the $\mathrm{R} \& \mathrm{D}$ project diverse resources and insights from multiple sources, it is useful to team up with them during the initialization phase. A number of techniques have been proposed to source knowledge widely from the external environment, such as scouting (Rohrbeck, 2010), sourcing (West \& Lakhani, 2008), as well as screening and signaling (Fontana et al., 2006). Future research may explore the detailed effect of collaboration in this phase, and the optimal combinations of different searching approaches as well as knowledge sources.

In the project-planning phase, the project successfully passes through initial selection and enters into a further development stage. The research direction and problem definition of the project become clear and committed resources are supposed to be in place. Since in this phase of development projects tend to rely more on internal decision-making and upper management support, overly relying on external partnerships may introduce noise into the decisionmaking and planning process. Moreover, numerous coordination and communication among partners may bring additional problems into the process. In sum, external partnerships may not be very beneficial for this stage of project development.

The third stage in the project life cycle is execution. In the project execution phase, the actual work of the project is performed. The involvement of external partners (both technology and market based) is supposed to be instrumental in solving project's problems in a timely and advanced manner.

The fourth phase of project development is termination. During this phase, the final outcome of the project is handed to its intended users (the business departments of the firm). Collaboration with internal business units in this phase may facilitate project transfer and smoothen the research result delivery. Most collaboration at this phase may relate to the identification of suitable business models and novel applications of the innovation that has been developed in the previous stages. 
In short, choosing the optimal involvement of different types of partners at a right moment in $\mathrm{R} \& \mathrm{D}$ projects should improve their performance. These types of studies are promising but are not yet executed. We, therefore, encourage scholars to analyze the timing of R\&D collaborations in the following years.

\subsubsection{Organizational Mode Choices of Collaboration and R\&D Project Success}

Organizational mode choice of R\&D collaborations will also influence R\&D project success. Collaborations in $\mathrm{R} \& \mathrm{D}$ projects can be organized in different ways. Formal collaborations have received a lot of attention in the literature and they do play a considerable role in R\&D project development. In formal collaboration, the targets and teams are clearly identified, and there is an agreement about the resources to be invested and the length of the collaboration period. Formal collaborations are in most cases contract-based agreements. Collaboration with partners is, however, not always formalized and "informal" relations play a crucial role in reality as well. Informal collaborations can take different shapes. Take for instance partnerships of firms in subsidized research and technology programs, scouting relationships, conference participations, partnerships in standard-setting organizations, long-term relationships with key technology partners, such as prominent universities and research labs, or key market players (key customers, first-tier suppliers, etc.), just to name a few. In other cases, collaboration is not formalized because of the nature of the collaboration such as crowdsourcing and online competitions. It is obvious that informal collaboration deserves more attention: First, it has been systematically underemphasized because of lack of reliable data, and second, firms are nowadays increasingly tapping into information from multiple informal knowledge sources (Tether \& Tajar, 2008).

An R\&D team can reach different objectives through different collaboration modes. Different mixes of formal and informal collaboration modes will best fit the needs of different R\&D projects. Research on the choice of optimal collaboration modes in $\mathrm{R} \& \mathrm{D}$ projects has not been developed so far. There is a burning need to make progress on this research theme.

\subsubsection{Other Determinants of Collaboration and R\&D Project Success}

There are many more factors that moderate or shape the impact of open innovation on R\&D projects' outcome. One of them is the technology fields, and their state of development, in which R\&D projects take place. Some technologies are emerging, others are established, some are relying critically on 
expensive R\&D-infrastructure while still other $R \& D$ projects need the input of large communities of creative people. All these factors will determine how collaboration has to be organized to boost the technological and financial outcome of R\&D projects.

Similarly, more propositions can be developed depending on the information embedded in the data about corporate $\mathrm{R} \& \mathrm{D}$ projects. We have mentioned before how information about the identity of the partners can substantially enrich our understanding on how open innovation works at the project level. The focal firm and its partners belong to particular industries, they have a specific position in the technology landscape and they are located in a specific country or city. With more detailed data about partners, we can seize new topics such as the role of geographical proximity or technological proximity in open innovation. Similarly, more detailed data about the R\&D team leader and members or about the organization and management of $R \& D$ projects opens up new possibilities to investigate the conditions under which open innovation plays a positive role in improving the success of $\mathrm{R} \& \mathrm{D}$ projects. In Figure 6.2 we cluster several determinants under different questions. Each of these factors will influence how a company organizes for open innovation at the level of R\&D projects, and how openness impacts on the innovative and financial performance of projects. We suggest that further research examines

\footnotetext{
- Why - the objectives or reasons why R\&D teams collaborate with external partners. The alignment of the firm's objectives with those of its partners.

- Who-Types of partners; optimal mix of partners; identity of partners.

- When-Collaboration timing; R\&D collaboration in different phases of project development.

- What-Technology fields involoved into collaborations; emerging or established technologies; radical vs. incremental innovation; modular vs. architectural innovation.

- Where-Geographical issues of collaboration in R\&D projects; choice and management of close and distant partners; influence of technological hotspots and location of existing R\&D labs.

- How-Organizational modes of collaborations in R\&D projects; management of collaborations in projects.
}

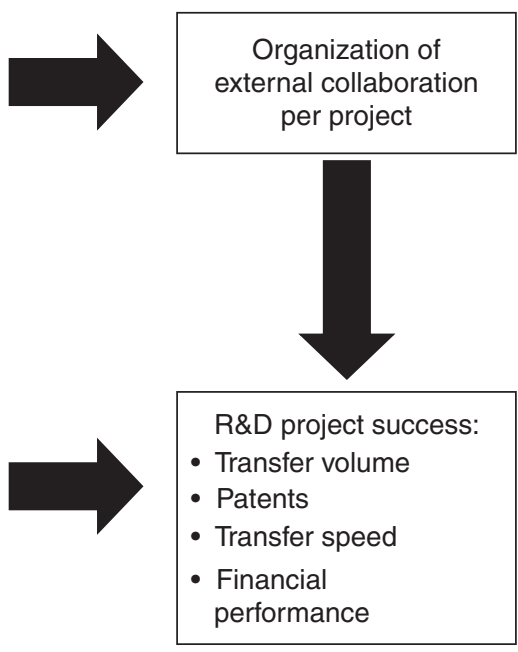

Figure 6.2 Factors affecting the organization of $R \& D$ projects and their outcome 
the relative importance of the suggested moderators of the open innovation project performance relationship.

\subsection{PLACING R\&D PROJECT RESEARCH INTO A BROADER PERSPECTIVE}

In the previous sections we have shown that studying $\mathrm{R} \& \mathrm{D}$ projects is important to advance open innovation research. Analyzing open innovation activities and their effects at the project level, however, does not decline the importance of other levels of analysis. In fact, the role of open innovation in R\&D projects can only be fully understood when the project level is linked to the firm and other observation levels. Examining open innovation activities in $\mathrm{R} \& \mathrm{D}$ projects can lead to great insights about the mechanisms of how collaboration with different partners enhances the technological and commercial success of projects, but we should also study how decisions about open innovation at the firm affect open innovation at the project level and vice versa. Think for instance about a firm's corporate growth strategy, where management may decide to explore growth options in a particular new technical domain. Linking up with external partners in $\mathrm{R} \& \mathrm{D}$ projects to explore new opportunities in new technological fields may have to be organized in a different way than open projects that serve ongoing innovation for the mainstream businesses. Open innovation at the R\&D project level should thus be related to corporate strategy and the ambidexterity literature to understand why managers open up R\&D projects and which partners they select to obtain specific strategic objectives. ${ }^{2}$

Likewise, we should not look at individual projects in isolation from each other but take the portfolio of $\mathrm{R} \& \mathrm{D}$ projects into account. $\mathrm{R} \& \mathrm{D}$ projects are embedded in the organizational context of the firm and, consequently, their value has to be derived from their position within the network of $\mathrm{R} \& \mathrm{D}$ projects in the firm. Firms not only set up a range of R\&D projects, they also coordinate and integrate internally developed and externally sourced knowledge across projects. Each individual project develops a piece of technological knowledge but a firm should also develop mechanisms to disseminate the knowledge and integrate it in the overall technology and business developments of the firm. Hence there is an urgent need to connect the project and the firm level to each other for two major reasons: First, we can only fully understand why firms engage in open innovation projects if we can position them within a firm's portfolio of projects and connect them to the overall innovation strategy of the firm. Second, one can only understand (firm level) concepts such as technology depth, breath, orientation, or absorptive capacity if they are related to open innovation activities in R\&D projects. An optimal level of breadth 
of technology search at the firm level for instance is after all the outcome of a mix of open and closed R\&D projects. The question is: how do companies decide on the mix of these projects? What are the reasons behind the choice for open or closed innovation in each project, and how is this choice affected by a company's prior experience with open innovation and the open innovation culture that it had developed previously? The most interesting research in open innovation could be developed at the intersection of these different levels of analysis. We badly need a multilevel analysis of open innovation to advance research in this field.

The interaction with other levels of analysis deserves more attention too. Success of open innovation in R\&D projects is most likely dependent on the quality and experience of individuals both in the R\&D team of the focal company as well as the individuals with whom they interact in the partnering organizations. Studying the role of individuals in open innovation is still uncharted territory, and interaction with the openness in R\&D project level investigations is not touched upon yet. A notable exception is the (yet) unpublished PhD thesis of Meijer (2013) who is investigating the role of individuals and team composition in alliance teams: this research pays attention to the teams in both companies who are establishing a technology alliance. The success of open R\&D projects is here further analyzed at the level of their components. Moreover, R\&D projects are no longer investigated as projects of an innovating company but as a concept that has to be explored as a joint management initiative of the innovating firm and its partner. ${ }^{3}$

\subsection{CONCLUSION}

Research at the project level can improve our understanding of how open innovation is implemented in large companies and how open innovation affects the technological and financial performance of firms. Open innovation activities mostly take place in $R \& D$ projects, which differ in many respects, such as the type of collaboration partners (technology vs. market partners), collaboration modes, timing of R\&D collaboration, technologies under development, strategies, the size and composition of project teams and the way projects are managed. Lowering the level of open innovation research from the firm to R\&D projects opens up possibilities to examine a broader set of factors that may determine how open innovation translates into a superior performance at the project and firm level. This will increase our understanding of the boundary conditions under which open innovation can work.

Several large companies record detailed information on the organization, management and open innovation practices of R\&D projects. Philips Research serves as a nice example. Starting from 2003, they recorded annually the 
open innovation practices of all R\&D projects executed by the central Philips Research departments, resulting in a panel dataset on the open innovation activities of several thousands of R\&D projects. Collaborating with companies to analyze available databases is suggested as an interesting route for academic researchers to move open innovation research further. A detailed analysis of these data also provides managers new insights on how R\&D projects have to be organized to generate more transfers, speed up product launches, and seize bigger market opportunities. Both academics and practitioners can win by opening up large-scale databases about R\&D project management.

Lowering the level of analysis to projects does however not imply that analyses at other levels are unimportant. There are clear links between decisions that are taken at the project level and other levels of analysis, such as individuals, R\&D units, firms, R\&D networks, sectoral, national and regional innovation ecosystems. Multi-level analyses that take into account the relationships of decisions that are taken at multiple levels could increase our current understanding of open innovation strategies.

\section{NOTES}

1. Cooper and Edgett (2012) assert that the stage gate process can easily be modified to incorporate open innovation. However, they do not operationalize what criteria to add or change in the stage gate model to do this.

2. This theme is for instance related to managerial considerations in opening $R \& D$ projects in core and non-core technologies. Interesting implications are formulated by Chesbrough and Schwartz (2007). We refer to Vanhaverbeke et al. (2012) for an empirical analysis of the role of alliances in core and non-core technology.

3. It is also possible to link open innovation practices in $\mathrm{R} \& \mathrm{D}$ projects to innovation ecosystems or R\&D networks (Nambisan \& Sawhney, 2011; Adner, 2012; Leten et al., 2013). 